\title{
Alcohol on drinking experience and attitudes towards sexual behaviors among female students in a Guangzhou technical secondary school
}

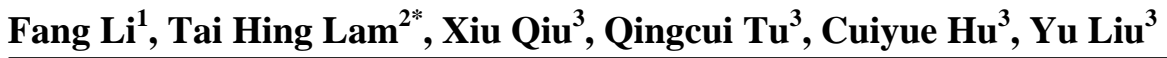 \\ ${ }^{1}$ Obstetrics and Gynecology Department of Guangzhou 8th People Hospital, Guangzhou, China \\ ${ }^{2}$ School of Public Health, The University of Hong Kong, Hong Kong, China \\ ${ }^{3}$ Obstetrics and Gynecology Department of Guangzhou Woman and Children Medical Center, Guangzhou, China \\ Email: "gz8hlf@,126.com
}

Received 20 May 2013; revised 22 June 2013; accepted 30 June 2013

Copyright (C) 2013 Fang Li et al. This is an open access article distributed under the Creative Commons Attribution License, which permits unrestricted use, distribution, and reproduction in any medium, provided the original work is properly cited.

\begin{abstract}
Objectives: To study the prevalence of alcohol drinking experience and attitudes towards sex behaviors among female students in a technical secondary school in Guangzhou, China. Methods: Cluster random sampling and a self-administered questionnaire survey. Results: 653 female students aged more than 18 years in a technical secondary school were surveyed. $112(17.2 \%)$ of them had not drunk alcohol. From the group with no alcohol experience to those who drank low level alcoholic drinks, and high level alcoholic drinks, or had got drunk (3 groups), there was an increasing trend of agreeing to love $(33.9 \%$, $56.9 \%$ and $63.3 \%$ respectively, $p<0.001$ ) and first sexual intercourse $(9.8 \%, 6.5 \%$ and $26.5 \%$ respectively, $\mathrm{p}<0.001)$ at young age ( $<20$ years). Compared to girls who drank alcohol, more girls with no alcohol experience did not know how to choose contraception methods. Conclusions: Alcohol drinking experience among female students in technical secondary school was associated with positive attitudes to young age love and sexual intercourse.
\end{abstract}

Keywords: Alcohol; Sexual Behaviour; Female Adolescent; Chinese

\section{INTRODUCTION}

In many countries, adolescents start drinking alcohol at young age. Studies from developed countries have found that adolescents with drinking experience are more likely to have unwilling or unprotected sexual intercourse. The earlier the teenagers start to drink alcohol, the greater probability they will have alcohol dependence or alco-

"Corresponding author. hol-related diseases in adulthood [1]. Research on this problem in developing countries is limited. Although Chinese girls drink much less than girls in the West, the relationship between drinking experience and attitudes towards sexual behaviours is unclear. During the 2011 adolescent health education campaigns, we carried out a survey to study the prevalence of alcohol drinking experience and attitudes towards sexual behaviors among female adolescents in a Guangzhou technical school. It is one of 157 public technical schools in Guangzhou. Most of students in technical school got lower scores at public entrance examination than those students in senior high school and were ready to work after graduating from technical school [2].

\section{METHODS}

Respondents: Female students aged more than 18 years in a full-time technical secondary school in Tianhe District, Guangzhou, China.

\section{Questionnaire}

The survey was carried out in a Guangzhou technical secondary school in 2011. Thirteen out of 22 classes were chosen randomly and all students present were invited to complete a questionnaire in the classroom. This anonymous and self-administered questionnaire included students' general information, experience of drinking alcoholic beverages and smoking, attitudes on age of beginning to fall in love and to have sexual intercourse, and choices of contraception methods and completed questionnaires were collected by our research staff. Participation was voluntary and all information provided would be kept confidential and only used by the researchers for statistical analysis. 


\section{STATISTICAL}

The statistical package SPSS17.0 was used for statistical analysis, including chi-square test and logistic regression.

\section{RESULTS}

\subsection{General}

All the 653 girls were aged over 18 (average 18.39 $( \pm 0.49))$ years. 112 girls $(17.2 \%)$ had never drunk while $443(67.8 \%)$ had tried low level alcoholic drinks and never got drunk. 39 girls (6\%) had tried spirits and never got drunk and 59 (9\%) had ever got drunk. 134 girls $(20.5 \%)$ were nonsmokers and they did not care about others smoking; 476 (73\%) were nonsmokers but opposed to their relatives and friends' habit of smoking. Only 43 (6.6\%) were smokers or ex-smokers.

\subsection{Age of First Love and First Sexual Intercourse}

352 girls (53.9\%) accepted first love under the age of 20 while 301 (46.1\%) only accepted it after 21 (Table 1). 66 girls $(10.1 \%)$ accepted first sexual intercourse under 20 while $587(89.9 \%)$ only accepted it after 21 (Table 2). 212 girls $(32.5 \%)$ did not know how to choose contraception methods. 333 girls chose condom while 108 girls chose, intrauterine device and other contraception methods (Table 3).

\subsection{Drinking and Acceptance of Age of First Love and Sex}

Girls who drank high level alcohol or got drunk were more likely to accept first lover under the age of 20 years than the other two groups (Table 3, 65.3\% versus 56.9\% and $33.9 \%, \mathrm{p}<0.001$ ) and to accept first sexual intercourse under 20 (Table 2, 26.5\% versus $6.5 \%$ and $9.8 \%$, $\mathrm{p}<0.001)$. However, more nondrinkers did not know how to choose contraception methods (Table 3, p < 0.001 ).

\subsection{Multivariate Analyses}

Because older girls were less likely to accept first love $($ Odds ratio, OR $)=0.77$ per year, 95\% CI: $0.635-0.933$, $\mathrm{p}<0.01)$ and first sex $(\mathrm{OR}=0 . \mathrm{xx}$ per year, 95\% CI: $\mathrm{xx}-$ $\mathrm{xx}, \mathrm{p}<\mathrm{xx}$ ) under 20, age was adjusted in logistic regression. In high level alcohol drinkers, the age adjusted OR $(95 \% \mathrm{CI})$ or first love and first sex under 20 was 5.32 $(2.72$ - 10.41) and $3.90(1.74-8.75)$ respectively, and that for knowing how to choose contraceptive methods was 2.74 (1.49 - 5.02) (Tables 1-3).

\section{DISCUSSION}

Drinking alcoholic beverage is popular in China. It was estimated 20 millions of new drinkers in China made the wine market increased more than 50\% in 2011 [3]. China accounted for almost $40 \%$ Asia alcohol market value.

Table 1. Accepted age of first love by alcohol drinking.

\begin{tabular}{|c|c|c|c|}
\hline & \multicolumn{2}{|c|}{ Accepted age of first love } & \multirow{2}{*}{$\begin{array}{c}\text { Age adjusted OR }(95 \% \mathrm{CI}) \\
\text { Acceptance of young age of first love }\end{array}$} \\
\hline & $\leq 20$ years $\mathrm{n}(\%)$ & $\geq 21$ years $\mathrm{n}(\%)$ & \\
\hline Never drink (reference group) & $38(33.9 \%)$ & $74(66.1 \%)$ & 1.00 \\
\hline Low alcohol level drinkers & $252(56.9 \%)$ & $191(43.1 \%)$ & $2.91^{*}(1.83-4.63)$ \\
\hline High alcohol level drinkers & $62(63.3 \%)$ & $36(36.7 \%)$ & $5.32^{*}(2.72-10.41)$ \\
\hline Total & $352(53.9 \%)$ & $301(46.1 \%)$ & \\
\hline
\end{tabular}

${ }^{*} \mathrm{p}<0.0001$.

Table 2. Accepted age of first sexual intercourse by alcohol drinking.

\begin{tabular}{cccc}
\hline & \multicolumn{2}{c}{ Accepted age of first sex } & $\begin{array}{c}\text { Age adjusted OR (95\%CI) } \\
\text { Acceptance of young age of first sex }\end{array}$ \\
\cline { 2 - 3 } & $\leq 20$ years n $(\%)$ & $\geq 21$ years n (\%) & 1.00 \\
\hline Never drink (reference group) & $11(9.8 \%)$ & $101(90.2 \%)$ & $0.71(0.34-1.50)$ \\
Low alcohol level drinkers & $29(6.5 \%)$ & $414(93.5 \%)$ & $3.90^{*}(1.74-8.75)$ \\
High alcohol level drinkers & $26(26.5 \%)$ & $72(73.5 \%)$ & 587 \\
Total & 66 & & \\
\hline
\end{tabular}

${ }^{*} \mathrm{p}<0.001$. 
Table 3. Knowing how to choose contraception measures.

\begin{tabular}{|c|c|c|c|c|}
\hline & \multicolumn{3}{|c|}{ Contraception measures knowledge of choosing } & \multirow{3}{*}{$\begin{array}{l}\text { Age adjusted OR }(95 \% \mathrm{CI}) \text { Knowing how } \\
\text { to choose }\end{array}$} \\
\hline & \multirow{2}{*}{ Don't know n (\%) } & \multicolumn{2}{|c|}{ Know } & \\
\hline & & Condom n $(\%)$ & Others n $(\%)$ & \\
\hline Never drink (reference group) & $49(43.8 \%)$ & $37(33 \%)$ & $26(23.2 \%)$ & 1.00 \\
\hline Low alcohol level drinkers & $141(31.8 \%)$ & $238(53.7 \%)$ & $64(14.4 \%)$ & $1.68^{*}(1.10-2.59)$ \\
\hline High alcohol level drinkers & $22(22.4 \%)$ & $58(59.2 \%)$ & $18(18.4 \%)$ & $2.74^{* *}(1.49-5.02)$ \\
\hline Total & $212(32.5 \%)$ & $333(51.0 \%)$ & $108(16.5 \%)$ & \\
\hline
\end{tabular}

${ }^{*} \mathrm{p}<0.05,{ }^{* *} \mathrm{p}<0.01$.

They consumed alcoholic beverage 11.6 liters/per person $x$ year $[4,5]$. This study showed that drinking experience was prevalent among the technical school girls in Guangzhou. Only $17.2 \%$ of them had never drunk alcohol. In a survey of middle school students in Guangzhou in $2004,63.1 \%$ had drunk alcohol at least than once [6]. In our study, about $80 \%$ had ever drunk alcohol. However, students in technical schools had lower academic standards, which may lead to high drinking prevalence. Further studies are needed to monitor the trend of drinking in adolescent.

Previous research in the West has found that adolescent drinking experience was associated with unprotected sex [7-9]. Although some surveys reported young drinking or drunk adults were inclined to experience non-consensual sex, more male students believed the girls were willing to $[9,10]$. Alcohol expectancy and myopia models showed alcohol affected many sexuality indices, alter their sexual decisions [11]. Because sexual behaviors are affected by social setting, culture and individual factors, different studies showed discrepancies on whether drinking could result in earlier sex $[12,13]$. The results were also different among different ethnic groups [14]. We have not found similar studies on this group of students in China. Hence, our report is the first in China to show that alcohol drinking was associated with more acceptance of first love and sex at young age in school. It was reported that $18 \%$ age $15-24$ unmarried outside school adolescents had sex in China [15]. But for those in senior school, only $4.4 \%$ of them had sex [16]. Alcohol might be one of high risk for them to have sex. Further studies are needed to study why alcohol experience had effect on early sex and how to change their behaviors.

Our report showed drinking experience was associated with more knowledge on how to choose contraception methods. Where the contraception knowledge came from and would it be enough to help them protect themselves were under concern because it was reported that drinking before sex was less likely to use contraception methods in young adults [17]. Sex education on Contraception should pay special attention on nondrinkers as about half of our subjects in survey without alcohol experience showed inadequate knowledge too.

Adolescent's drinking behavior can adversely affect physical and mental development and on the health and quality of life in adulthood [1], and can lead to serious social problems. Compared with western countries, the prevalence of adolescent drinking is lower in China. But our results indicate that alcohol drinking could be a widespread problem among adolescent girls which might impact on their dating, love and sex experience. More research and sex education are needed to control the emerging epidemic of drinking among girls and young women

\section{REFERENCES}

[1] Grillo, D.H.J. (2012) Global status report: Alcohol and young people.

[2] (2012) Address list of technical schools in Guangzhou. http://wenku.baidu.com/view/3bb3cb1da76e58fafab0034 b.html

[3] Jingdaily (2012) Bottoms up: China's alcohol imports jump 58 percent.

http://www.wine.cn/en.php/News/showdetail/article_id/1 $\underline{2629}$

[4] (2012) China: The Asia top alcohol comsuming center. http://sp.chinadaily.com.cn/wine/20120712/39669.html

[5] (2012) Alcoholic drinks in China. www.datamonitor.com

[6] Wang, J., Deng, X.J., Wang, J.J. et al. (2009) Substance use, sexual behaviors, and suicidal ideation and attempts among adolescents: Findings from the 2004 Guangzhou youth risk behavior survey. Public Health, 123, 116-121. doi:10.1016/j.puhe.2008.10.013

[7] Elvin, J. (2008) Intoxication, capacity to consent, and the sexual offences act 2003. King's Law Journal, 19, 151157.

[8] Gunby, C., Carline, A. and Beynon, C. (2010) Alcoholrelated rape cases: Barristers' perspectives on the sexual 
offences act 2003 and its impact on practice. The Journal of Criminal Law, 74, 579-600. doi:10.1350/jcla.2010.74.6.670

[9] Gunby, C., Carline, A., Bellis, M.A., et al. (2012) Gender differences in alcohol-related non-consensual sex; Crosssectional analysis of a student population. BMC Public Health, 12, 216.

[10] Beres, M.A. (2007) Spontaneous sexual consent: An analysis of sexual consent literature. Feminism \& Psychology, 17, 93-108. doi:10.1177/0959353507072914

[11] George, W.H. and Stoner, S.A. (2000) Understanding acute alcohol effects on sexual behaviour. Annual Review of Sex Research, 11, 92-124.

[12] Grossman, M., Kaestner, R. and Markowitz, S. (2005) An investigation of the effects of alcohol policies on youth STDs. In: Lindgren, B. and Grossman, M., Eds., Advances in health economics and health services research. Substance abuse: Individual behavior, social interactions, markets and politics, Elsevier, Oxford.

[13] Bellis, M.A., Hughes, K., Calafat, A., Juan, M., Ramon, A., Rodriguez, J.A., Mendes, F., Schnitzer. S. and Phil-
lips-Howard, P. (2008) Sexual uses of alcohol and drugs and the associated health risks: A cross sectional study of young people in nine European cities. BMC Public Health, 8, 155-165.

[14] Rothman, E.F., Wise, L.A., Bernstein, E., et al. (2009) The timing of alcohol use and sexual initiation among a sample of black, Hispanic, and white adolescents. Journal of Ethnicity in Substance Abuse, 8, 129-145. doi: 10.1186/1471-2458-8-155

[15] Sun, X., Zhu, G.-R., Ji, C.-Y., et al. (2012) Analysis on sex behavior and its impact factors among outside school adolescents in outflow area. Chinese Journal of School Health, 8, 35-36. doi:10.1080/15332640902896984

[16] Song, Y., Ji, C.-Y., Xing, Y., et al. (2008) Sexual behaviors among urban senior middle school students in 18 provinces in China. Chinese Journal of School Health, 12, 1079-1081

[17] Bailey, J.A., Fleming, C.B., Catalano, R.F., et al. (2012) Romantic relationship characteristics and alcohol use: Longitudinal associations with dual method contraception use. Journal of Adolescent Health, 50, 450-455. 